1 2

\title{
3D quantitative analysis of graphite morphology in high strength cast iron by high-energy $x$-ray tomography
}

\author{
Chihpin Chuang ${ }^{\text {a }}$, Dileep Singh ${ }^{\mathrm{a},{ }^{*}}$, Peter Kenesei ${ }^{\mathrm{b}}$, Jon Almer ${ }^{\mathrm{b}}$, \\ John Hryn ${ }^{\text {a }}$, Richard Huff ${ }^{\mathrm{c}}$ \\ ${ }^{a}$ Energy Systems Division, \\ Argonne National Laboratory \\ 9700 South Cass Avenue, \\ Argonne, IL 60439, USA \\ b Advanced Photon Source, \\ Argonne National Laboratory \\ 9700 South Cass Avenue, \\ Argonne, IL 60439, USA \\ ${ }^{\mathrm{c}}$ Manufacturing Technology, PD\&GT, \\ Caterpillar Inc. \\ 14009 North Old Galena Road, \\ Mossville, IL 61552, USA \\ * Corresponding author. Tel.: +1 630252 5009; fax: +1 6302525568. \\ E-mail address: dsingh@anl.gov (D. Singh).
}

March 2015

To be submitted to Scripta Materialia managed by UChicago Argonne, LLC, under Contract No. DEAC02-06CH11357 with the U.S. Department of Energy. The U.S. Government retains for itself, and others acting on its behalf, a paid-up, nonexclusive, irrevocable worldwide license in said article to reproduce, prepare derivative works, distribute copies to the public, and perform publicly and display publicly, by or on behalf of the Government. 
3D quantitative analysis of graphite morphology in high strength cast iron by high-energy $x$-ray tomography

Chihpin Chuang, Dileep Singh*, Peter Kenesei, Jon Almer, John Hryn, and Richard Huff

\begin{abstract}
:
The size and morphology of the graphite particles play a crucial role in determining various mechanical and thermal properties of cast iron. In the present study, we utilized high-energy synchrotron x-ray tomography to perform quantitative 3D-characterization of the distribution of graphite particles in high-strength compacted graphite iron (CGI). The size, shape, and spatial connectivity of graphite were examined. The analysis reveals that the compacted graphite can grow with a coral-tree-like morphology and span several hundred microns in the iron matrix.
\end{abstract}


Despite the discovery and development of many advanced material systems in the past few decades, a century old material, cast iron, still remains an important material used in today's energy, machinery and transportation industries. One of the main reasons is due to its wide range of mechanical and physical properties [1, 2], which are tunable through well-controlled advanced casting technologies, and competitive production cost. It is well recognized that the size and morphology of the graphite phase in cast iron play a crucial role in determining its various properties. Therefore, extensive efforts have been made to manipulate the morphology and distribution of the graphite phase through the combination of techniques such as changing the chemistry of the melt and altering the type and application of inoculant treatment [3-7]. This ability to tune the graphite phase allows the material to be optimized, within limits, to a set of properties for a given application.

The relationship between the microstructure and the final properties of cast alloys has been the center of many studies [1]. Despite this, the understanding of correlations among manufacturing parameters, resulting microstructures and alloy properties are not conclusive and sometimes controversial. This is primarily because an accurate description of the graphite morphology and distribution is not available. The current industrial standard to evaluate the microstructure of graphite in cast iron relies mainly on the subjective comparison of 2D metallography images of the product and ASTM/ISO Standard images $[8,9]$. However, what really matters is the 3D structure of the graphite and its spatial arrangement within the alloy, which cannot be judged reliably from $2 \mathrm{D}$ projections. Some progress has been made in recent years to address these issues [10-14], such as the 3D characterization of graphite morphology by destructive FIB-tomography $[12,13,15,16]$. A series of studies using FIB and TEM tomography have showed the superiority of 3D characterization over 2D. Velichko et al.[13] have demonstrated that a classification of complex graphite particles can be done unambiguously and accurately by FIB-tomography analysis using various 3D geometrical parameters, including volume, shape, and spatial connectivity[16]. They further showed that phase connectivity, which cannot be obtained by traditional 2D analysis, is one of the determining factors for the cast iron properties.

Despite their usefulness, these techniques often involve long, complicated and sometimes tedious sample preparation procedures. While the information can be very high resolution, and provide good mechanistic understanding, it is localized and destructive. On the other hand, the mechanical properties, which are one of the most important factors for the application of cast iron, are usually determined by the statistical ensemble of parameters in a bulk material, such as the nodularity and morphology of graphite. In addition, the labor-intensive nature of these techniques increases the cost substantially when statistical representation is needed. Cost is often the biggest concern for industry. 
In the present study, we utilize synchrotron X-ray tomography to investigate the size and morphology of graphite in cast iron. The volume probed is in the range of several hundred cubic millimeters. The study aims to accurately and quantitatively correlate the morphology and distribution of graphite particles in the cast iron to the process parameters.

The base material analyzed is a high strength compacted-graphite iron (CGI) produced by Caterpillar Inc. for use in heavy-duty engine components. The carbon and silicon content from this heat were $3.68 \%$ and $1.81 \%$ respectively. The sample is a cylindrical rod of $2.1 \mathrm{~mm}$ diameter and $\sim 20 \mathrm{~mm}$ length that was EDM-cut from the center region of a 2 " thick cast block typically used for thermal analysis as shown in Figure 1(a). The X-ray tomographic experiment was conducted at the 1-ID beamline at the Advanced Photon Source (APS) at Argonne National Laboratory (ANL). The experiment used a $70 \mathrm{KeV}$ monochromatic X-ray beam with energy bandwidth of $10^{-3}$. At this energy level, the X-ray transmission for $2 \mathrm{~mm}$-thick iron is $\sim 27 \%$ while the carbon (graphite phase) is nearly transparent (> 99\% transmission). The selection of energy ensured the measurement has sufficient transmitted intensity for detection through the thickest area of the cross section and sufficient intensity resolution to provide the best contrast (absorption-based) between the iron and graphite phases. The X-ray was collimated by a series of slits to a $1.9 \mathrm{~mm}(\mathrm{H}) \times 1 \mathrm{~mm}(\mathrm{~V})$ rectangle incident on the specimen, which was mounted at the rotation center of a high precision rotation stage. The transmitted X-rays were projected to a 25 um thick, single-crystal LuAG:Ce $\left(\mathrm{Lu}_{3} \mathrm{Al}_{5} \mathrm{O}_{12}\right.$ : $\left.\mathrm{Ce}\right)$ scintillator which was placed $200 \mathrm{~mm}$ down-stream from the sample. Visible light from the scintillator was collected by a series of optics and recorded by a $2048 \times 2048$ pixel CCD camera. The $200 \mathrm{~mm}$ sample to scintillator distance was used in order to obtain phase contrast in the image, which can greatly enhance the visibility of submicron features, including interfaces between phases. Such enhancements also simplify the procedure of post-reconstruction image processing. In the pure absorption contrast regime, the resolution of present experimental setup is roughly $2 \mu \mathrm{m}$. More detail of the experimental setup can be found in Ref [17].

For a typical tomographic measurement, a series of 901 radiographic images were taken at $0.2^{\circ}$ intervals during a $180^{\circ}$ rotation of the specimen. The entire diameter of the sample was kept within the field-of-view (FOV) of the detector during data collection, which took 15 minutes for a given $1 \mathrm{~mm}$-thick volume. Since the diameter of the sample is slightly larger than a single FOV, the sample was translated horizontally by $1 \mathrm{~mm}$ and re-measured to cover the entire diameter. The FOVs were overlapping by about 700 um to assure the proper parameterization of the stitching. Then the sample was translated vertically to measure the next volume. These FOVs were subsequently digitally stitched together to create a $1.8 \mathrm{~mm}$ tall and $3.1 \mathrm{~mm}$ wide FOV. These stitched images plus 20 white images (image without a sample), 10 each before and after the measurement, and 10 dark images, were used to reconstruct the 3D internal structure 

reconstruction, tomographic images of the specimen with the resolution of $\sim 2 \mu \mathrm{m}$ were obtained. The reconstructed volumes were then processed and analyzed by Matlab ${ }^{\circledR}$ and Image ${ }^{\circledR}$ to obtain 3D morphology and distribution of graphite phases in the specimen. The visualization of the volumes was achieved by open-source software, Paraview $^{\circledR}$.

A typical 2D tomographic image from the measurement is shown in Figure 1 (b). Since the main focus of the current study is the morphology and size distribution of graphite particles in the specimen, one needs to, first, verify that the features obtained from $x$-ray $\mathrm{CT}$ images are the features usually found from traditional 2D metallography technique. The same specimen, after the x-ray CT measurement, was mechanically sliced and polished to prepare the metallography-grade surface following the standard metallography procedure, then examined by an optical microscopy (OM). Both the OM and the corresponding tomography images of the same region are presented in Figure 1 (b) and (c), respectively. The graphite phase that is lighter in atomic weight absorbs less x-ray energy, therefore exhibits darker in the tomographic image while the iron phase is brighter. The colors are consistent with those in OM image. Both nodular graphite (NG) and compact-graphite (CG) particles can be observed in the image and the features shown in this tomographic slice are almost identical to those on the real sample surface (under OM) with just a slightly blurred image due to the lowered image resolution in tomography ( $2 \mu \mathrm{m}$ in tomo vs $<0.5 \mu \mathrm{m}$ in $\mathrm{OM})$. The slightly brightened edge is the edge enhancement from the phase-contrast part of the signal. In general, the tomography image preserves the overall shape and size of graphite particles. It is clear that tomography can correctly capture the morphology of graphite particles in the specimen in a non-destructive manner. Therefore, the analysis based on tomography measurement can be directly compared with the traditional $2 \mathrm{D}$ metallography analyses for the size, morphology and volumetric distribution of graphite phase within the sample.

With a series of continuous $2 \mathrm{D}$ images through various depth of the material, a $3 \mathrm{D}$ model of the graphite particles in the measured volume were built with image segmentation techniques[20]. In Figure 1(b), we focus on a particle that appears to be a NG with a tail. After 3D reconstruction, we found that it belongs to a larger coral treelike structure that has large flat and rounded branches. Here, we denote it as CG1. The morphology of CG1 fits the typical description of a compacted graphite structure. The complete 3D model of CG1 is shown in Figure 1 (d). The red arrow indicates the nodule that is enclosed by a red dash line in Figure 1 (b).

To provide a quantitative description of the particles, several geometric parameters were evaluated, including volume, surface area, sphericity and diameter of the minimum bounding sphere. The results are summarized in Table I. CG1 has a volume 
of 230,412 voxels ( 1 voxel $\equiv 1$ pixel $^{3} \sim 1 \mu \mathrm{m}^{3}$ ) and a maximum Feret diameter of $211 \mu \mathrm{m}$. Here, the Feret diameter is defined as a measure of an object's size along a specific direction. In 3D, it is equivalent to the diameter of a minimum-bounding sphere that can enclose the whole object.

The analysis of the 3D structure reveals information which can either not be seen or possibly misinterpreted with standard 2D analysis. Several irregularly shaped particles near the node, as indicated by a red-dash line in Figure 1(c), are actually part of the same CG1 structure. This analysis also provides the ability to unambiguously classify the type of the particle being analyzed, which is critical in determining the microstructureprocess parameter relationship of cast iron. For example, the node in Figure 1(b) could be identified as either a NG or a CG in 2D analysis depending on where the surface is cut, as illustrated in Figure 1(e).

SEM and Energy-Dispersive-Spectroscopy (EDX) were used to further analyze the particle in Figure 1. The chemistry of the nuclei and elemental mapping of the particle are shown in Figure 2. We found the nucleus of this nodule contains $\mathrm{Mg}, \mathrm{Al}, \mathrm{Fe}$ and $\mathrm{Si}$. These elements are constituents of the inoculant that was used during alloy casting process. A few other spherical nodes similar to the one being analyzed were found to attach to the CG1 structure. Since the connection between the nodule and the whole CG structure is narrow as shown in the SEM image, it is possible that they nucleated independently, then grew and connected to each other at later stage of the solidification. However, we cannot exclude the possibility that a single nodule was nucleated and then, due to the local chemistry and cooling rate of the surrounding melt, branched into a tree-like structure as proposed by Pan et al.[21].

3D analysis was applied to a segment of the full volume measured, which was $2 \mathrm{~mm}$ in diameter by $0.35 \mathrm{~mm}$ high. This analysis volume was limited by the computing power and the memory of the computer; particularly as the time required to run a calculation is scaled exponentially to the analyzed volume. Within this volume there were a total of 21,446 individual particles identified and the geometrical parameters of each were determined. Since the resolution of the tomography measurement is around $2 \mu \mathrm{m}$, the cut-off volume of the individual particle for the analysis was set to 40 voxels, i.e. particles smaller than 40 voxels were excluded from the analysis. Nodularity is one of the most common and important parameters in describing the structure of a CGI. Here, sphericity was chosen as a key index to categorize the morphology of the graphite. It is defined as

$$
\Psi=\frac{\sqrt[3]{\pi\left(6 V_{p}\right)^{2}}}{A_{p}}
$$

where $V_{p}$ is the volume of the particle and $A_{p}$ is the area of the particle. The distribution of the particles as a function of sphericity as well as the cumulative volume of the 

between 0.35 and 0.56 , but the curve of the cumulative volume shows majority of the graphite volume is contributed by the particles with low sphericity, which are CG particles similar to the one shown in Figure $1(d)$. There are only 29 particles $(0.13 \%$ of total particles) whose sphericity are less than 0.1 , but they posses $48.8 \%$ of total graphite volume.

In theory, the sphericity of a perfect sphere will equal to 1, but due to the size of the voxel with respect to the size of the particle and the algorithm for surface area calculation, the sphericity of a perfect sphere in the present study is between 0.55 0.62. After reviewing tens of particles of different sphericity, we use sphericity of 0.4 as a criterion to determine the NG. There are 20,429 particles (95.3\% of total particle counts) that have the sphericity larger than 0.4 , and the size distribution of these NG are plotted in Figure 3(b). It shows a normal distribution with the peak centered at $10 \mu \mathrm{m}$ and a Full-Width-Half-Maximum of $~ 8 \mu \mathrm{m}$. The mean diameter is the averaged diameter of each individual particle.

Figure 4(a) shows the spatial distribution of the NGs in the analyzed volume. The large NGs (with a diameter larger then $30 \mu \mathrm{m}$ ) are shown in red and the small NGs (with a diameter smaller then $20 \mu \mathrm{m}$ ) are shown in blue. The distribution distinctly partitions the volume into dense and sparse regions which might represent the eutectic cells. The NGs are not uniformly dispersed within the volume, but rather aggregate in-between these eutectic cells. The large NGs seem to surround the sparsely packed region, while the smaller ones are distributed more evenly between the cells. The distribution of large CG particles (top 29 in terms of volume) is plotted in Figure 4(b) for comparison. Each individual CG particle was assigned a unique color with the color map ranging from blue (the largest in volume) to red (the smallest in volume). As expected, the CGs are somewhat filled into the cell region defined by the distribution of NGs. The largest CG structure (labeled in A) has a maximum Feret dimension of $\sim 1.6 \mathrm{~mm}$. The CG1 particle from Figure 1 is labeled in B. It should be noted that the largest CGs in terms of volume, shown in Figure 4(b), all have part of their structure touching the edge of the volume, meaning they were truncated by the volume boundary. Therefore, the size distribution of the CGs is not plotted because the entire picture of each individual CGs is not revealed completely. Thus, such analysis could be misleading. As indicated earlier, the size of the volume can be analyzed is limited by the computing power and memory size of the computer, more powerful computer or computing cluster is needed to have accurate analysis of CG particles. Nevertheless, current results still provide important information that have never been obtained by other characterization techniques. The enormous size, distribution and morphology of CGs explain why CGI has improved thermal conductivity over ductile iron, but with strength levels between ductile iron and gray iron. The flat, rounded branches help in suppressing the initiation of cracks, so the 
tensile as well as fatigue strength is higher than in grey iron, whose relatively sharpedged graphite flakes create greater stress concentrations.

In summary, high energy X-ray tomography was shown to provide excellent insight into the microstructure of compacted graphite iron. Large volumes (in millimeter size) of the sample can be analyzed in a relatively short time and provide results with high accuracy. In particular, the size, morphology and spatial connectivity of different graphite particles within a bulk volume were analyzed. The results show that the nodularity of the sample is $35 \%$, and the averaged diameter of nodular graphite is $12 \mu \mathrm{m}$. 3D structural analysis revealed that the compacted graphite can grow to a coraltree-like morphology as large as a few millimeters in the iron matrix. Finally, it is noted that these measurements can be readily extended to in-situ studies of microstructural evolution at elevated temperatures, to provide further understanding of cast iron solidification process.

\section{Acknowledgement:}

The material used in this study is based upon work supported by the Department of Energy under Award Number(s) DE-EE0005980. This study was supported by Caterpillar Inc., under a Work-for-Others Agreement 85F53. CAT, CATERPILLAR, their respective logos, "Caterpillar Yellow," the "Power Edge" trade dress as well as corporate and product identity used herein, are trademarks of Caterpillar and may not be used without permission. Part of this research used resources of the Advanced Photon Source, a U.S. Department of Energy (DOE) Office of Science User Facility operated for the DOE Office of Science by Argonne National Laboratory under Contract No. DE-ACO2$06 \mathrm{CH} 11357$.

\section{Disclaimer:}

This report was prepared as an account of work sponsored by an agency of the United States Government. Neither the United States Government nor any agency thereof, nor any of their employees, makes any warranty, express or implied, or assumes any legal liability or responsibility for the accuracy, completeness, or usefulness of any information, apparatus, product, or process disclosed, or represents that its use would not infringe privately owned rights. Reference herein to any specific commercial product, process, or service by trade name, trademark, manufacturer, or otherwise does not necessarily constitute or imply its endorsement, recommendation, or favoring by the United States Government or any agency thereof. The views and opinions of authors expressed herein do not necessarily state or reflect those of the United States Government or any agency thereof. 
Reference:

[1] J.R. Davis, ASM International. Handbook Committee., Cast irons, ASM International, Materials Park, OH, 1996.

[2] D.M. Stefanescu, R. Ruxanda, L.P. Dix, International Journal of Cast Metals Research, 16 (2003) 319-324.

[3] I.C. Riposan, M.; Kelley, R.; Barstow, M.; Naro, R. L., AFS Transactions, 93 (2003).

[4] T.G. Skaland, O.; Grong, T., Metallurgical Transactions a-Physical Metallurgy and Materials Science, 24 (1993) 2321-2345.

[5] H.K. Itofuji, Y.; Yamanoto, S.; Inoyama, N.; Yoshida, H.;Chang, B. , Transactions of the American Foundrymen's Society, 91 (1983).

[6] P.C.L. Liu, C.R.; Kimura, T.; Pan, E.N., Transactions of the American Foundrymen's Society, 88 (1980).

[7] P.C.L. Liu, C.R.; Kimura, T.; Pan, E.N., Transactions of the American Foundrymen's Society, 89 (1981).

[8] ASTM Standard E2567, 2013a, "Determining Nodularity And Nodule Count In Ductile Iron Using Image Analysis", ASTM International, West Conshohocken, PA, 2003, DOI: 10.1520/E2567-13, http://www.astm.org., 2013.

[9] ASTM Standard E2567, 2006, "Test Method for Evaluating the Microstructure of Graphite in Iron Castings", ASTM International, West Conshohocken, PA, 2003, DOI: 10.1520/a0247-06, http://www.astm.org., 2006.

[10] G. Fischer, J. Nellesen, N.B. Anar, K. Ehrig, H. Riesemeier, W. Tillmann, Materials Science and Engineering a-Structural Materials Properties Microstructure and Processing, 577 (2013) 202-209.

[11] J.M. Li, L. Lu, M.O. Lai, Materials Characterization, 45 (2000) 83-88.

[12] A. Velichko, C. Holzapfel, F. Mucklich, Advanced Engineering Materials, 9 (2007) 3945.

[13] A. Velichko, C. Holzapfel, A. Siefers, K. Schladitz, F. Mucklich, Acta Mater., 56 (2008) 1981-1990.

[14] R. Ruxanda, D.M. Stefanescu, International Journal of Cast Metals Research, 14 (2002) 207-216.

[15] A. Hatton, M. Engstler, P. Leibenguth, F. Mucklich, Advanced Engineering Materials, 13 (2011) 136-144.

[16] A. Velichko, F. Mucklich, International Journal of Materials Research, 100 (2009) 1031-1037.

[17] A. Khounsary, P. Kenesei, J. Collins, G. Navrotski, J. Nudell, 11th International Conference on Synchrotron Radiation Instrumentation (SRI), Lyon, FRANCE, 2012.

[18] B.A. Dowd, G.H. Campbell, R.B. Marr, V. Nagarkar, S. Tipnis, L. Axe, D.P. Siddons, Conference on Developments in X-Ray Tomography II, Denver, Co, 1999, pp. 224-236.

[19] Y.X. Wang, F. De Carlo, I. Foster, J. Insley, C. Kesselman, P. Lane, G. von Laszewski, D. Mancini, I. McNulty, M.H. Su, B. Tieman, Conference on Developments in X-Ray

Tomography II, Denver, Co, 1999, pp. 318-327.

[20] J.C. Russ, Boca Raton : CRC/Taylor and Francis, Boca Raton, 2007.

[21] E.N. Pan, K. Ogi, C.R. Loper Jr., AFS Trans., 90 (1982) 509-527. 
Table I. Geometrical parameters of the CG particle in Figure 1. The analysis is based on 3D structure model.

\begin{tabular}{|c|c|c|c|c|c|}
\hline $\begin{array}{l}\text { Volume } \\
\text { (voxel) }\end{array}$ & $\begin{array}{l}\text { Surface } \\
\left.\text { (pixel }^{2}\right)\end{array}$ & $\begin{array}{l}\text { SA/V ratio } \\
\left(\text { pixel }^{-1}\right)\end{array}$ & $\begin{array}{c}\text { Dia. of } \\
\text { equivalent } \\
\text { sphere (pixel) }\end{array}$ & Sphericity & $\begin{array}{l}\text { Dia. of min. bounding } \\
\text { sphere (pixel) }\end{array}$ \\
\hline 317797 & 168340 & 0.53 & 84.6 & 0.05 & 210.5 \\
\hline \multicolumn{6}{|c|}{$\begin{array}{l}\text { Definitions: } \\
\text { Volume: total number of voxels (voxel) } \\
\text { SA/V: surface area to volume ratio (pixel }{ }^{-1} \text { ) } \\
\text { Equivalent Sphere: a sphere whose volume is equal to the volume of the particle } \\
\text { Sphericity: an index to show how spherical a particle is, defined in Eq. } 1 \text {. The sphericity is } 1 \text { for a } \\
\text { perfect sphere. } \\
\text { Minimum bounding sphere: the smallest sphere that can enclose the entire particle }\end{array}$} \\
\hline
\end{tabular}




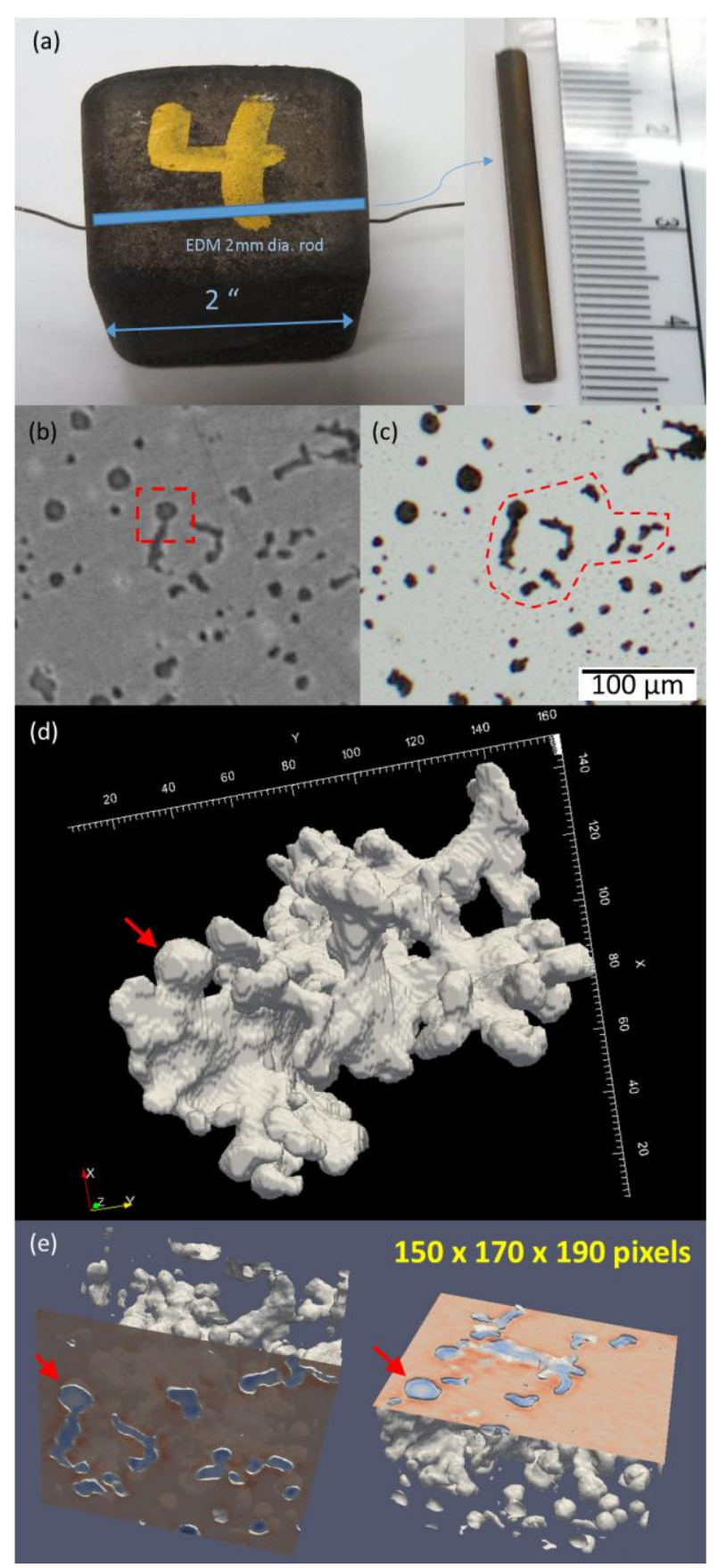

Figure 1 (a) The 2 " casting block and a $2 \mathrm{~mm}$ diameter rod that is EDM cut out of the sample. (b) A typical slice of tomographic image obtained in the present study. (c) An un-etched metallography image of the same region in (b) under optical microscope (OM). (d) The reconstructed 3D model of the graphite particles in (b). It shows that the 2D features observed in $(b, c)$ belong to a coral tree-like structure with flat, rounded branches that span $\sim 200 \mu \mathrm{m}$ in the iron matrix. (e) The left is the slicing surface and the graphite structure beneath the surface. The right side is the same CG structure but sliced in different orientation. It shows the same feature (red arrow) could be identified as either NG or CG in 2D analysis depending on where you slice it. 


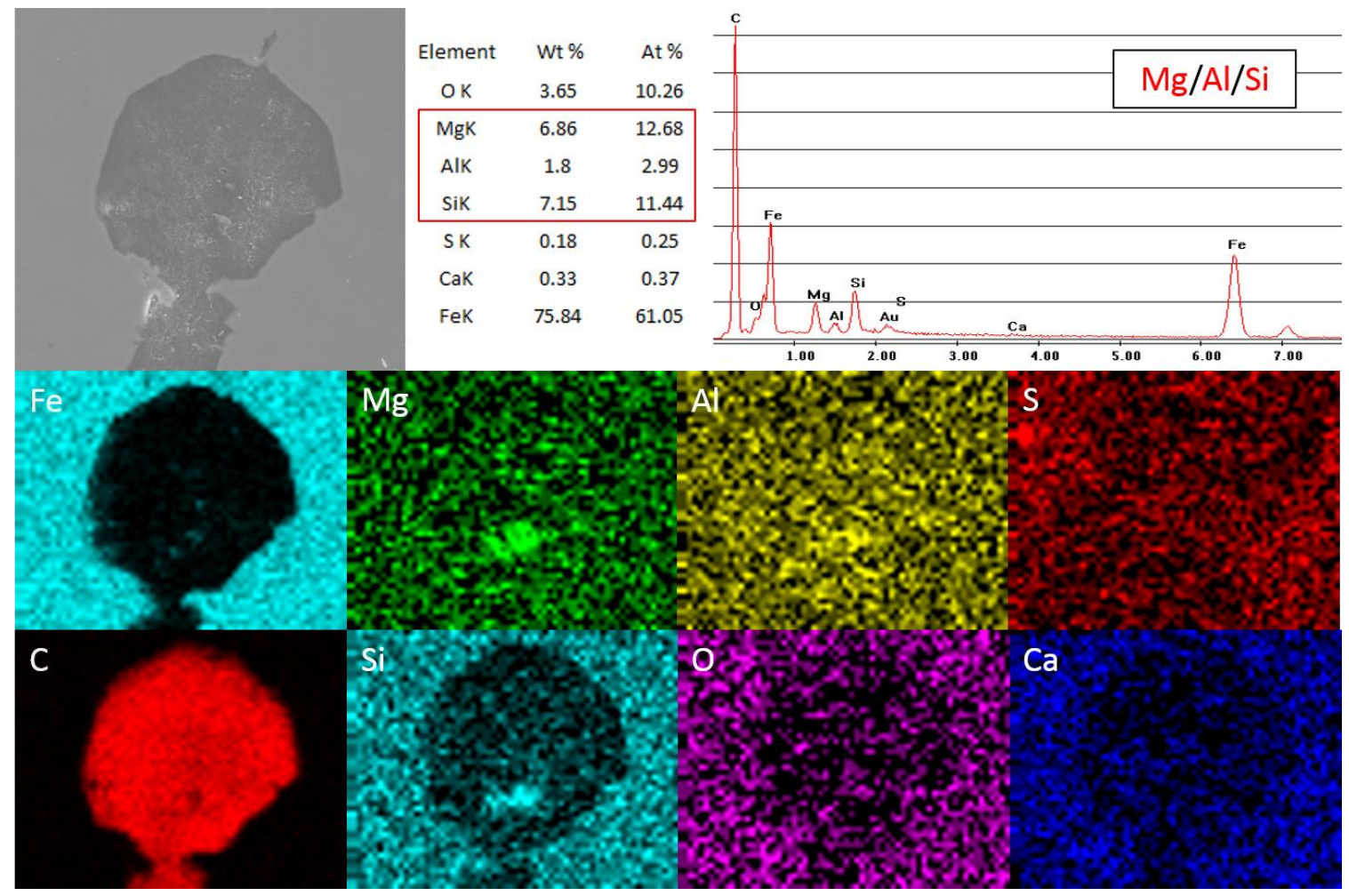

Figure 2 Elements mapping of the nodular graphite which is attached to a CG structure in Figure 1. The core of this particle is exposed by mechanical polish and it contains $\mathrm{Mg}$, $\mathrm{Al}$ and $\mathrm{Si}$. 
(a)

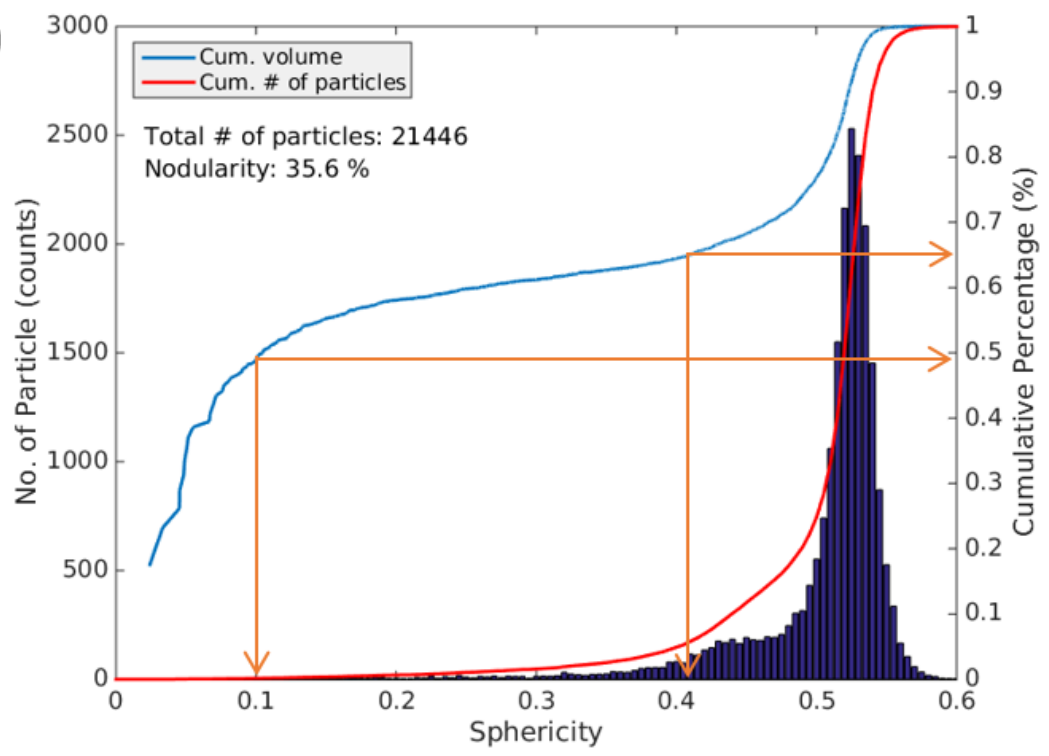

(b)

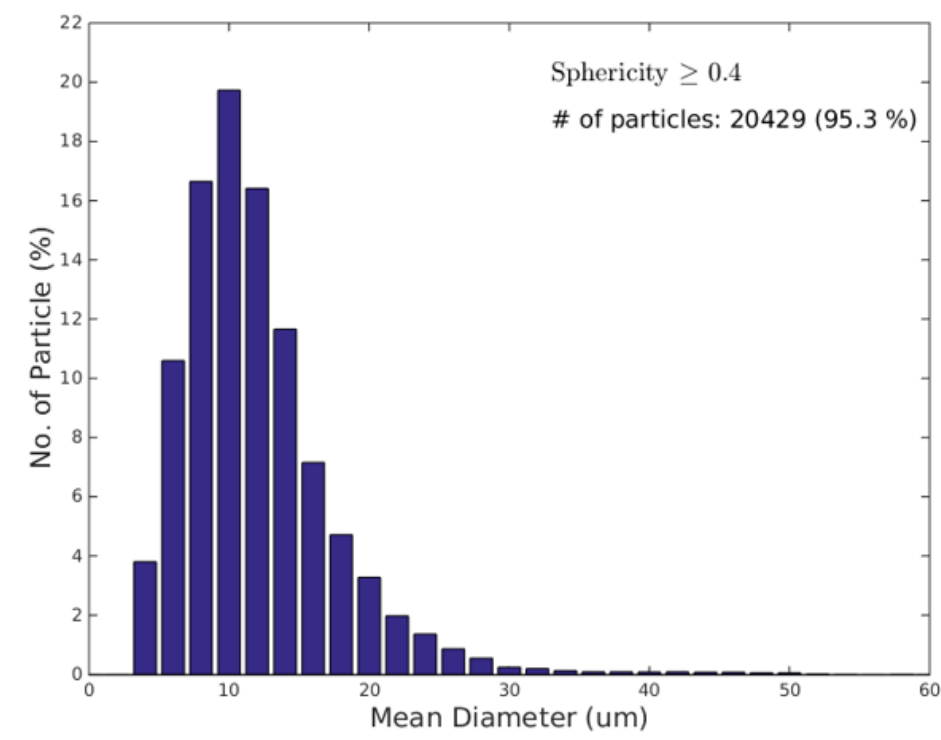

Figure 3 (a) Particle distribution as a function of sphericity. (b) Size distribution of particles that have the sphericity over 0.4 . These particles are categorized as nodular graphite (NG). 


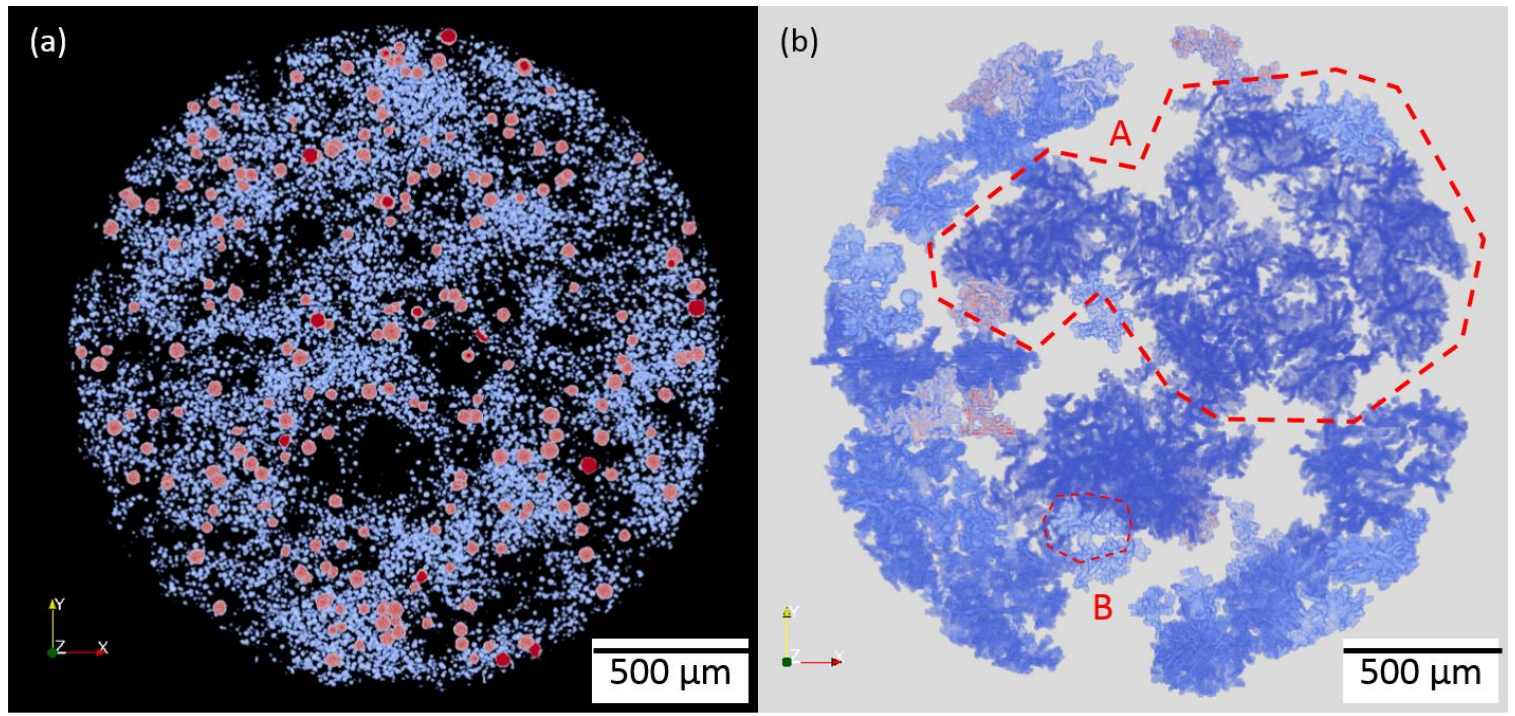

Figure 4 (a) The distribution of nodular graphite (NG) in the analyzed volume $(2 \mathrm{~mm}$ in diameter and $350 \mu \mathrm{m}$ thick volume). The red represents the NG with a diameter larger than $30 \mu \mathrm{m}$ and the blue are smaller NGs (diameter $<20 \mu \mathrm{m}$ ) (b) Large CGI particles (sphericity $<0.1$ ) in the same volume. Each color represent an isolated/independent structure. It clearly shows CG has an inter-connected tree-like structure. Particle B consists of the CG structure in Figure 1. 